Revista Destaques Acadêmicos, Lajeado, v. 10, n. 4, 2018. ISSN 2176-3070

DOI: http://dx.doi.org/10.22410/issn.2176-3070.v10i4a2018.2043

http://www.univates.br/revistas

\title{
MOBILIDADE URBANA SUSTENTÁVEL ESTUDO DE CASO NO MUNICÍPIO DE TEUTÔNIA
}

\author{
Juliane Elisa Stahlhöfer ${ }^{1}$, Marcelo Arioli Heck²
}

Resumo: $\mathrm{O}$ trabalho tem como tema um estudo sobre as características da mobilidade urbana sustentável nas cidades, realizando um estudo de caso no município de Teutônia. Através de pesquisas gerais sobre a cidade, é elaborado um diagnóstico do local, assim como também, são estudadas as propostas do Plano de Mobilidade Urbana para o município. A partir da comparação dos conceitos estudados sobre urbanismo sustentável, densidades, vias permeáveis, usos do solo, distribuição de equipamentos urbanos e espaços abertos pela cidade com os problemas encontrados no município de Teutônia em relação a mobilidade urbana, são elaboradas estratégias para resolver a dificuldades deste sistema no município. Como resultado dos estudos, conclui-se que para aprimorar a sustentabilidade é necessário um centro urbano com espaços de convivência e facilidade de acessos, tornando mais próximos a moradia, o trabalho e o lazer, facilitando as possibilidades de deslocamento dos pedestres. Para tanto, é importante aprimorar a mobilidade urbana, integrando esta ao planejamento urbano.

Palavras chave: Cidades, Mobilidade Urbana, Urbanismo Sustentável.

\section{INTRODUÇÃO: UMA LEITURA SOBRE A MOBILIDADE DE TEUTÔNIA}

A mobilidade urbana é considerada tema importante em relação ao planejamento das cidades e do urbanismo sustentável. Pode-se perceber que atualmente, muitas cidades apresentam problemas rotineiros com congestionamentos em certos horários do dia, altos índices de acidentes nas ruas, pouca utilização de transporte coletivo e meios de locomoção nãomotorizados e um excesso de uso do automóvel individual. A realidade de Teutônia não é diferente.

1 Graduanda do Curso de Arquitetura e Urbanismo da Universidade do Vale do Taquari.

2 Doutorando em Planejamento Urbano e Regional (UFRGS), Mestre em Planejamento Urbano e Regional(UFRGS). Docente do Curso de Arquitetura e Urbanismo da Universidade do Vale do Taquari. 
Teutônia é subdivida em três núcleos principais, que têm como centralidades os bairros Teutônia, Languiru e Canabarro. Estes bairros ficam distantes entre si, divididos pelo Arroio Boa Vista e a área de APP (Área de Preservação Permanente) entre os bairros Teutônia e Languiru; e o bairro Centro Administrativo (entre os bairros Languiru e Canabarro), com um grande vazio urbano e áreas pouco ocupadas e desenvolvidas. Ainda o bairro Alesgut, ao Oeste da cidade, possui a barreira pela ERS-128 (Via Láctea) que o separa do bairro Languiru.

A conexão entre os bairros é realizada por duas vias principais: a ERS128 (Via Láctea) e a "Estrada Velha" (Ruas Daltro Filho, Três de Outubro e Carlos Arnt). Com a descontinuidade da malha viária e o isolamento dos bairros entre si, o tráfego é prejudicado, pois se acumula nestas duas vias principais, gerando congestionamentos em certos horários do dia.

Existe também o problema dos vazios urbanos que formam grandes áreas centrais desocupadas. Estas, dificultam a mobilidade urbana, pois localizam-se no centro, em locais que possuem infraestrutura urbana próxima, e estão atualmente sendo utilizadas como área agrícola. Isto causa o crescimento desordenado da cidade, visto que a ocupação urbana tende a se expandir em direção às periferias, o que provoca um aumento das distâncias entre a moradia, o trabalho e os equipamentos públicos.

O objetivo geral do trabalho, é promover uma discussão sobre a mobilidade urbana, partindo das ideias do Novo Urbanismo, da mobilidade sustentável na visão atual, e comparando-a com alguns problemas em relação a mobilidade urbana no município de Teutônia.

\section{REFERENCIAL TEÓRICO}

O capítulo apresenta uma pesquisa de embasamento teórico para o desenvolvimento deste trabalho, com foco nos temas de urbanismo sustentável, tratamento de vias, equipamentos urbanos e espaços abertos.

\subsection{A importância do urbanismo sustentável nas cidades}

A mobilidade sustentável na visão atual, traz o incentivo a diversidade modal, a proteção ao meio ambiente e a saúde humana, valorizando os meios de transporte não motorizados, o adensamento populacional, a compacidade e os usos mistos. O PlanMob: Caderno de Referência para elaboração de Plano de Mobilidade Urbana (2015), explica que a mobilidade na visão tradicional apresentava uma forte valorização para veículos motorizados, devido a rapidez do transporte em longas distâncias. Com isto, os investimentos das cidades foram sendo direcionados para melhorias de vias e na maior oferta de estacionamentos. Houve também, uma maior dispersão na ocupação do solo e nos usos separados. Todos estes fatores, levaram a população a preferir ainda mais a utilização de veículos motorizados, pois as distâncias entre 
equipamentos tonaram-se mais longas, o espaço nas ruas destinado ao pedestre foi sendo reduzido pelos estacionamentos e faltava a animação urbana, pela pouca diversidade de usos.

Assim como foi apresentado pelo PlanMob, o autor Gehl (2013) também assegura que não é suficiente apenas dispor o espaço para a circulação de pedestres e ciclistas, é necessário que a cidade possibilite o contato direto com a sociedade em torno dela. Para isto, é importante que o espaço público seja ocupado por muitas pessoas e de diferentes grupos. O autor ainda explica a cidade viva, com a revelação de sinais de interação social, pois a partir da presença de outras pessoas, assemelha-se a um lugar convidativo e agradável, enquanto os lugares vazios trazem a sensação de que existe algo errado. "O que importa não são números, multidões ou o tamanho da cidade, e sim a sensação de que o espaço da cidade é convidativo e popular". (GEHL, 2013, p. 63)

De acordo com Leite (2012), as cidades se reinventam. Os projetos urbanos devem renovar e instrumentalizar os vazios centrais. O desenvolvimento destas áreas faz a cidade se voltar para dentro, ao invés de expandi-la, compactando-a e deixando-a mais sustentável. Isto gera uma rede de núcleos compactos e densos, otimizando as infraestruturas e liberando territórios verdes.

Farr (2013) resume os princípios mais básicos do urbanismo sustentável: um bom sistema de transporte público, poder deslocar-se a pé em uma infraestrutura de alto desempenho e utilizar como valores centrais, a densidade e o acesso humano a natureza. Ainda define três elementos essenciais para a estrutura do urbanismo: bairros, distritos e corredores. Os bairros devem ser compactos, respeitar os pedestres e ter uso misto. Os distritos também devem ser compactos e respeitar os pedestres, no entanto, precisa ter uso único, como por exemplo, um campus universitário ou parque industrial. Os corredores, intercomunicam bairros e distritos. Os benefícios sociais da vida no bairro são maiores quando integram definição, compacidade, totalidade, conexão e biofilia.

Castello (2008) menciona a organização da unidade de vizinhança de Clarence Perry, que leva em consideração a localização dos equipamentos, a distribuição espacial e a hierarquização do sistema viário. A intenção deste modelo era apresentar uma célula de viver bem, em um local tranquilo e equipado com as atividades complementares bem localizadas e distribuídas de acordo com a necessidade da população, criando assim, um ambiente residencial qualificado e que incentive a participação comunitária. Já Farr (2013) aponta deficiências neste modelo de unidade de vizinhança, como a falta do transporte público e tipos de habitação variados, o desalinhamento das ruas com as outras ruas dos bairros próximos e a falta de referência em relação às infraestruturas. Ele propõe a noção de bairro sustentável.

Segundo Farr (2013) o tratamento da rua, unidades de vizinhança ou bairros, influenciam diretamente no estilo de vida e comportamento das pessoas. Pois, quando se possui um ambiente agradável e funcional, com uma 
infraestrutura adequada, as pessoas se sentem mais entusiasmadas a usufruir do espaço. Isso contribui também na saúde da população, que aumenta o índice de atividade física e diminui os gastos com serviços de saúde.

Existem algumas diferenças nas propostas de bairro sustentável e da unidade de vizinhança. A unidade de vizinhança, limita-se por vias arteriais e rotas de grande fluxo, já o bairro, tem seu limite definido por caminhos verdes com habitats e infraestrutura. Na sua dimensão, considera-se a unidade de vizinhança como um círculo com raio de $400 \mathrm{~m}$, medida confortável para as pessoas caminharem a pé, enquanto o bairro, trabalha com a ideia de corredores de desenvolvimento, com transporte público e densidades maiores em seus arredores, diferente da unidade de vizinhança, aonde o centro é a escola. No bairro, a escola de ensino fundamental pode ser compartilhada com outros bairros próximos.

Todavia, muitas das propostas entre o bairro e a unidade de vizinhança são semelhantes. Pode-se citar como exemplo: a diversificação de usos do solo; a densidade, tornando a área mais compacta e facilitando a implantação de mobiliário urbano nas ruas, assim como a distribuição dos equipamentos urbanos; a valorização dos pedestres e ciclistas em relação aos automóveis particulares; a criação de espaços agradáveis para o convívio com o meio ambiente e a facilidade de encontro com outras pessoas; e, a proximidade do comércio, serviço, trabalho e equipamentos urbanos com a moradia. A conexão entre todos estes pontos de uso diário, é levado em consideração, na proposta de melhorar o espaço urbano, tornando o local mais agradável.

\subsection{Densidade urbana}

A densidade é um tema de grande importância no novo urbanismo. A densidade habitacional fornece uma das mais fortes correlações entre qualquer variável com o uso do automóvel, mas apenas parte deste efeito se deve a densidade isolada. Existem outros fatores onde a densidade serve como um representante comum: o preço do estacionamento, o comércio local, a intensidade do transporte público, a qualidade dos pedestres, entre outros. (LEITE, 2012)

Segundo Leite (2012), as cidades sustentáveis são compactas. Maiores densidades otimizam a infraestrutura urbana e propiciam maior qualidade de vida pela sobreposição de usos (habitacional, comercial e serviços), eficiência energética, melhor uso das águas e redução da poluição. O modelo é baseado em um sistema de mobilidade urbana eficiente, que conecta os núcleos adensados em rede, melhorando o transporte público e criando um desenho urbano que incentive a caminhada e o ciclismo.

Gehl (2013) também aborda a densidade como um fator importante para a vida na cidade. Segundo o autor, é necessária uma combinação de bons espaços públicos que sejam convidativos e uma boa quantidade de pessoas 
que queira utilizá-los. Mas ele também lembra que uma densidade alta mal planejada, prejudica a cidade, pois nos locais com prédios muito altos e com grandes densidades, as ruas tornam-se muito escuras, barulhentas e mesmo possuindo o espaço de circulação necessário, não são convidativas.

Cidades vivas requerem estrutura urbana compacta, densidade populacional razoável, distâncias aceitáveis para serem percorridas a pé ou de bicicleta e espaço urbano de boa qualidade. A densidade, que representa quantidade, deve ser combinada com a qualidade sob a forma de bons espaços urbanos. (GEHL, 2013, p. 69)

Para a sustentação do transporte público, é mais fácil atrair e reter os usuários em corredores com alta densidade urbana. A relação entre densidade populacional e o transporte público é essencial para o urbanismo sustentável. Conforme estudos, um ônibus local com no mínimo, paradas a cada $800 \mathrm{~m}$ e 20 ônibus por dia necessita de uma densidade residencial mínima de 10 unidades de habitação por hectare. Em um nível intermediário, com 40 ônibus por dia, a densidade mínima sobe para 17,5 e o nível frequente, com 120 ônibus por dia, exige uma densidade de 37,5. Estes valores podem variar, de acordo com o tamanho do centro da cidade e a distância entre a área residencial e o centro. (FARR, 2013)

\subsection{Vias permeáveis ao pedestre}

O sistema viário pode ser definido como um conjunto de canais de circulação e de movimento. A rua possui um papel muito importante, pois é ela que permite a movimentação da cidade. $O$ conjunto dessas vias de circulação formam a malha urbana, na qual cada via tem características distintas sendo que ela deve ser dimensionada e configurada de acordo com o papel que desempenha, formando assim, a hierarquia viária. Todo sistema viário urbano, é formado por, no mínimo, três tipos de vias: arteriais, coletoras e locais. As vias arteriais e rotas de grande fluxo funcionam como limites físicos da unidade de vizinhança, enquanto que as vias locais facilitam a circulação interior, mantendo um baixo fluxo viário. (CASTELLO, 2008)

As vias locais devem ser pensadas como um espaço de equilíbrio entre o veículo e o pedestre. Para isso, devem possuir estruturas seguras, agradáveis e que estimulem o sentido de comunidade: áreas de descanso e locais de interação, pontos de parada de ônibus, sinalização e passeios alargados junto aos equipamentos comerciais. Algumas ações projetuais têm a capacidade de transformar as ruas e trazer importantes mudanças na interação social da comunidade. (CASTELLO, 2008)

Farr (2013) afirma que a permeabilidade de um lugar é considerada pelas características das vias públicas e dos empreendimentos privados junto a elas. Seus níveis de permeabilidade podem ser classificados por elementos de 
composição do lugar e quanto ao seu aspecto e espírito. As ruas, os bairros e as diretrizes são flexíveis. Se o espírito é atendido, atinge-se também os níveis de qualidade. Ainda considera que, um resultado ruim pode ser compensado se existirem altos índices de permeabilidade ao pedestre, presença de escolas e espaços de uso misto em um raio de $400 \mathrm{~m}$ da maioria das casas, acesso à natureza e aos espaços abertos, e automóveis andando em baixa velocidade.

As ruas completas são projetadas para atender todos os modais de transporte. Essas vias servem de suporte para empreendimentos voltados aos bairros compactos, permitindo áreas de uso misto e permeáveis ao pedestre. Também possibilitam a utilização de diferentes modais de transporte, como transporte público, uso de automóveis, bicicletas ou caminhadas. O processo de desenho das vias sustentáveis integra a rua à forma e à função dos usos do solo do entorno, atendendo a todos os tipos de deslocamento. As orientações são baseadas para o uso de ambientes urbanos com baixas velocidades (menos de $55 \mathrm{~km} / \mathrm{h})$. (FARR, 2013)

Gehl (2013) também aborda o assunto sobre as ruas compartilhadas. Explica que, em uma ideia geral, estas ruas dão oportunidade para todos poderem usufruir do espaço, lado a lado, com um bom contato visual. Nesta configuração, raramente acontecem acidentes sérios, no entanto, pedestres e ciclistas necessitam sempre estar atentos ao trânsito, o que diminui a qualidade e a prioridade destes nas ruas.

Farr (2013) aponta alguns fatores a serem considerados na geração de deslocamentos dentro da cidade:

- Densidade de habitação ou locais de trabalho: à medida que a densidade aumenta, as taxas de geração de deslocamentos caem significativamente, pois mais usos ficam disponíveis a uma distância que pode ser percorrida a pé e a área de captação dos meios de transporte público aumentam, até chegar a um ponto no qual se torna possível um serviço frequente.

- Diversidade de tipos de uso do solo: quando os empregos, as moradias e os serviços estão a uma distância que pode ser percorrida a pé, o uso do automóvel cai, especialmente naqueles $80 \%$ de deslocamentos que não se relacionam com a ida ao local de trabalho.

- Projeto permeável ao pedestre: quando caminhar é um prazer, os indivíduos estarão dispostos a caminhar distâncias maiores até seus destinos.

- Acesso a destinos regionais: a frequência dos serviços de transporte público locais e o número de destinos regionais atendidos influencia o comportamento dos usuários.

- Estacionamento pago: a cobrança de estacionamento tem mais impacto no número de deslocamentos do que a soma de todas as demais medidas de gestão da demanda do transporte. 
- Transporte público: à medida que a frequência e a qualidade do transporte público aumentam, as taxas de uso de veículos particulares diminuem. Para isso, é importante que o transporte público seja rápido, frequente, regular e oferecido o dia inteiro e também no início da noite. Estes benefícios no transporte público, podem resultar no benefício extra da criação de um ambiente orientado para o pedestre.

- Permeabilidade ao ciclista e ao pedestre: as mudanças no ambiente construído têm impacto sobre o número de ciclistas e pedestres. As pequenas quadras possuem maior número de pedestres em comparação as superquadras. O ideal seria a formação de quadras com aproximadamente $100 \mathrm{~m}$ de lado.

Conforme Gehl (2013), atualmente, os responsáveis pelo planejamento de tráfego têm uma variedade de ruas para escolher: ruas apenas para veículos, ruas apenas para pedestres e ciclistas, ruas de preferência para pedestres, entre outros vários tipos de ruas com velocidades e características diversas. $\mathrm{O}$ autor ainda lembra que, para escolher o tipo de rua e soluções para o tráfego, é sempre importante partir da dimensão humana, tornando o deslocamento pela cidade confortável e seguro. Para tanto, é necessária especial atenção às crianças, jovens, idosos e pessoas com necessidades especiais. "O tráfego funciona com base no princípio de que a transição entre tráfego rápido e lento não acontece na porta das residências, mas nos limites da cidade". (GEHL, 2013, p. 95)

O PlanMob: Caderno de Referência para elaboração de Plano de Mobilidade Urbana (2015), apresenta uma tabela de incidências prováveis de diversos temas relacionados ao planejamento das ruas e do espaço urbano ao seu entorno, de acordo com as necessidades de cada cidade, em relação ao número de habitantes. Para as cidades menores, de 20 mil a 60 mil habitantes, este plano destaca alguns temas, como: integrar a mobilidade com o planejamento e uso do solo, hierarquizar o sistema viário e organizar a circulação, criar espaços adequados para pedestres e ciclistas, promover a acessibilidade universal, oferecer condições de segurança nas vias, acessibilidade de transporte coletivo e escolar também para as áreas rurais e a estruturação institucional.

Além do planejamento das ruas, Gehl (2013) também relaciona à segurança do espaço público de acordo com a sua utilização, pois, quanto mais pessoas caminham pela cidade e passam tempo nos espaços públicos, melhor é a segurança, tanto real, quanto a percebida. A presença de mais pessoas torna o lugar melhor e mais seguro. Fora a movimentação das pessoas que transitam na rua, acompanhar o que acontece lá também é algo interessante para os moradores dos edifícios em seu entorno, o que também amplia a segurança do local.

A vida nas ruas tem um impacto sobre a segurança, mas a vida ao longo da rua também tem um papel considerável. Áreas urbanas com diversidade de funções proporcionam todo o tempo, mas atividades dentro e perto das edificações. Áreas habitacionais, em especial, 
significam boas conexões com os espaços comuns importantes da cidade e um reforço acentuado da segurança real e da percebida, mesmo à noite. Então, ainda que a rua esteja deserta, nas áreas residenciais, as luzes das janelas enviam um sinal reconfortante de que há pessoas por perto. (GEHL, 2013, p. 99)

Gehl (2013) destaca a importância da iluminação à noite. Tanto a boa iluminação sobre as pessoas e rostos, quanto uma iluminação razoável nos cantos, recuos, pisos e degraus das vias de principais circulações de pedestres, gerando maior conforto e segurança às pessoas.

\section{DIAGNÓSTICO}

A cidade de Teutônia localiza-se no Vale do Taquari, região central do estado do Rio Grande do Sul, distante 108km de Porto Alegre. Confronta-se com os municípios de Westfália, Imigrante, Colinas, Estrela, Fazenda Vilanova, Paverama, Brochier, Poço das Antas, Barão e Boa Vista do Sul.

Seus principais acessos intermunicipais se dão através da RSC-453 (Rota do Sol), ERS-419 e BR-386. Além destes, também existem os acessos secundários: Estrada Municipal Padre Jesuíta Pedro Lenz (pela Linha Lenz Estrela), Estrada Santa Rita (Estrela), Rua Beno Fiegenbaum e Rua Maurício Cardoso (por Westfália).

O município é subdividido em seis bairros: Teutônia, Languiru, Canabarro, Alesgut, Centro Administrativo e Boa Vista. Os três primeiros, mais antigos, apresentam uma melhor distribuição de usos do solo, formando pequenos núcleos de bairro que funcionam de forma independente. Estes bairros são separados entre si, devido as barreiras naturais, a ERS-128 (Via Láctea) e por vazios urbanos.

A população no censo de 2010 foi de 27.272 pessoas, possuindo uma densidade demográfica de 152,68 hab $/ \mathrm{km}^{2}$, conforme dados do Instituto Brasileiro de Geografia e Estatística (IBGE). Destas, 23.322 pessoas residem na zona urbana e 3.950 pessoas na zona rural. A estimativa populacional para 2018 é de 32.676. (SCHAEFFER , 2018) 
Figura 1 - Densidades dos bairros: hab/ha

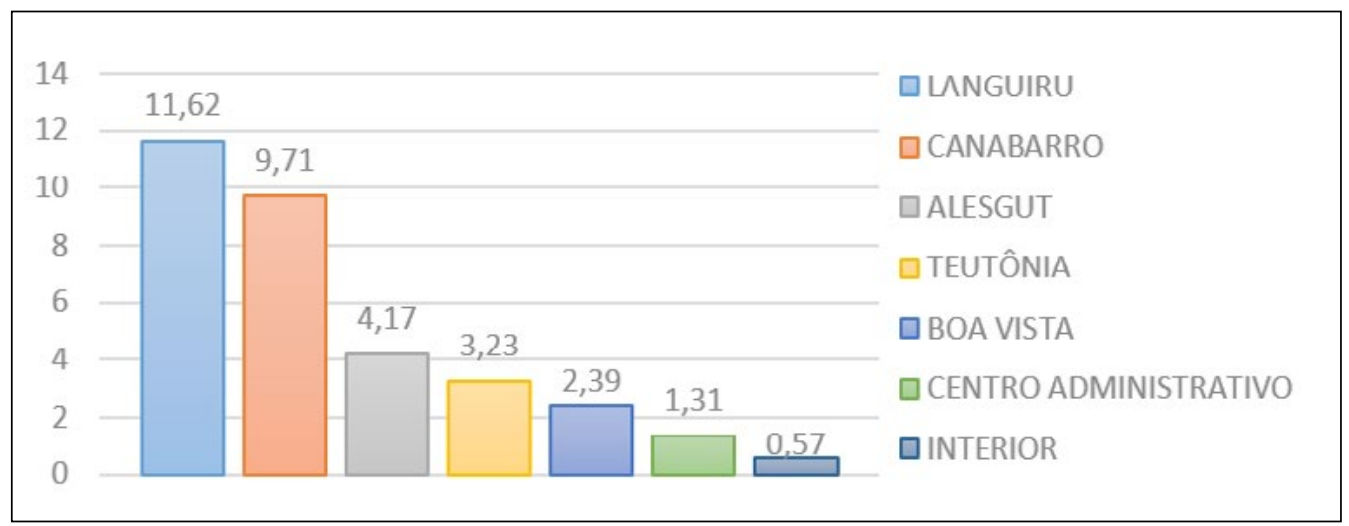

Fonte: Autora (2018).

O site www.populacao.net.br apresenta a distribuição das pessoas entre os bairros. Analisando o gráfico de densidades, observa-se que os bairros Languiru e Canabarro possuem as maiores densidades, enquanto que o restante possui baixa densidade. Este resultado comprova que a população em alguns locais está muito dispersa e que existe a necessidade de diminuir o perímetro urbano para se obter uma melhor densidade.

Figura 11 - Densidade Demográfica (hab./ha- Senso 2010)

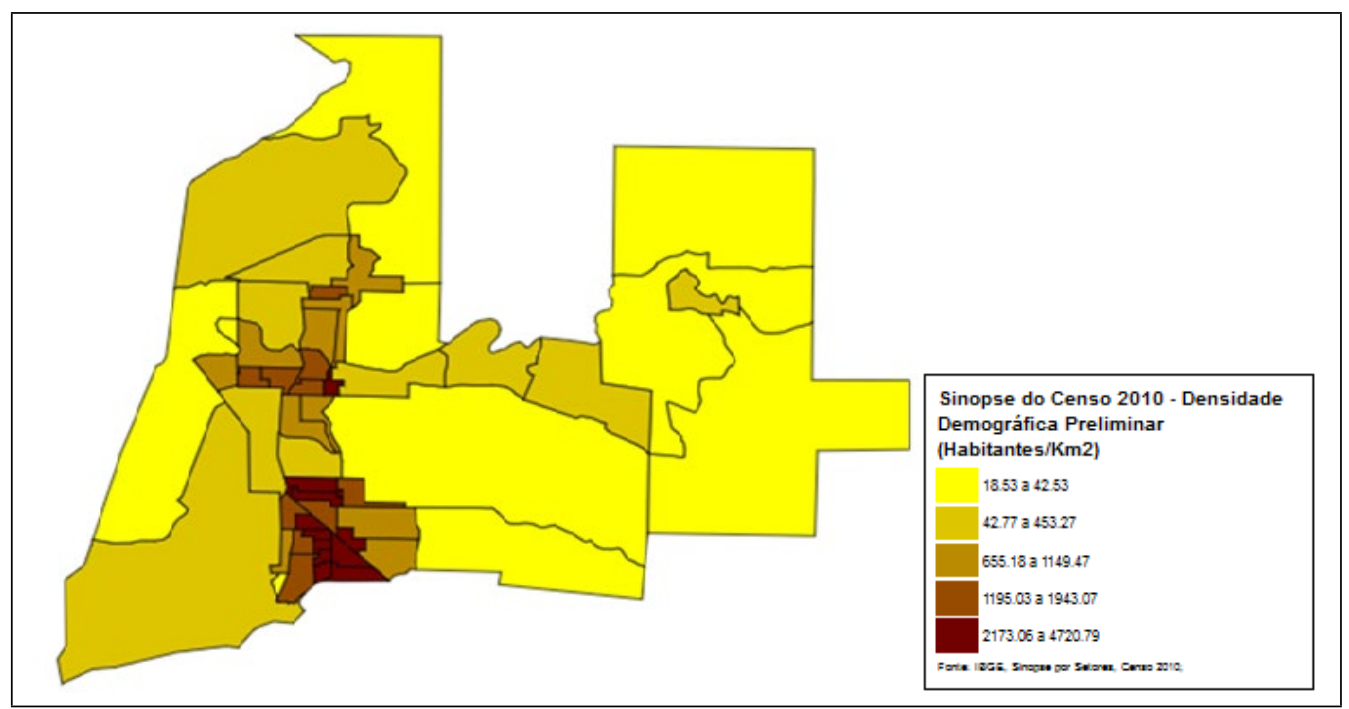

Fonte: Sinopse IBGE [2010].

O mapa de densidade demográfica apresenta de forma bem clara a distribuição populacional do município, conforme os dados já indicados no 
gráfico anteriormente. A maior concentração da população encontra-se no bairro Canabarro, aonde chega a uma densidade máxima de 4.720,79 hab./ $\mathrm{km}^{2}$. O interior, mesmo possuindo a segunda maior quantidade de habitantes, geralmente, possui as menores densidades, devido a sua área ser muito maior, tornando a população mais dispersa. Assim, apresenta densidade mínima de $18,53 \mathrm{hab} . / \mathrm{km}^{2}$.

Figura 18 - Evolução da frota de Teutônia

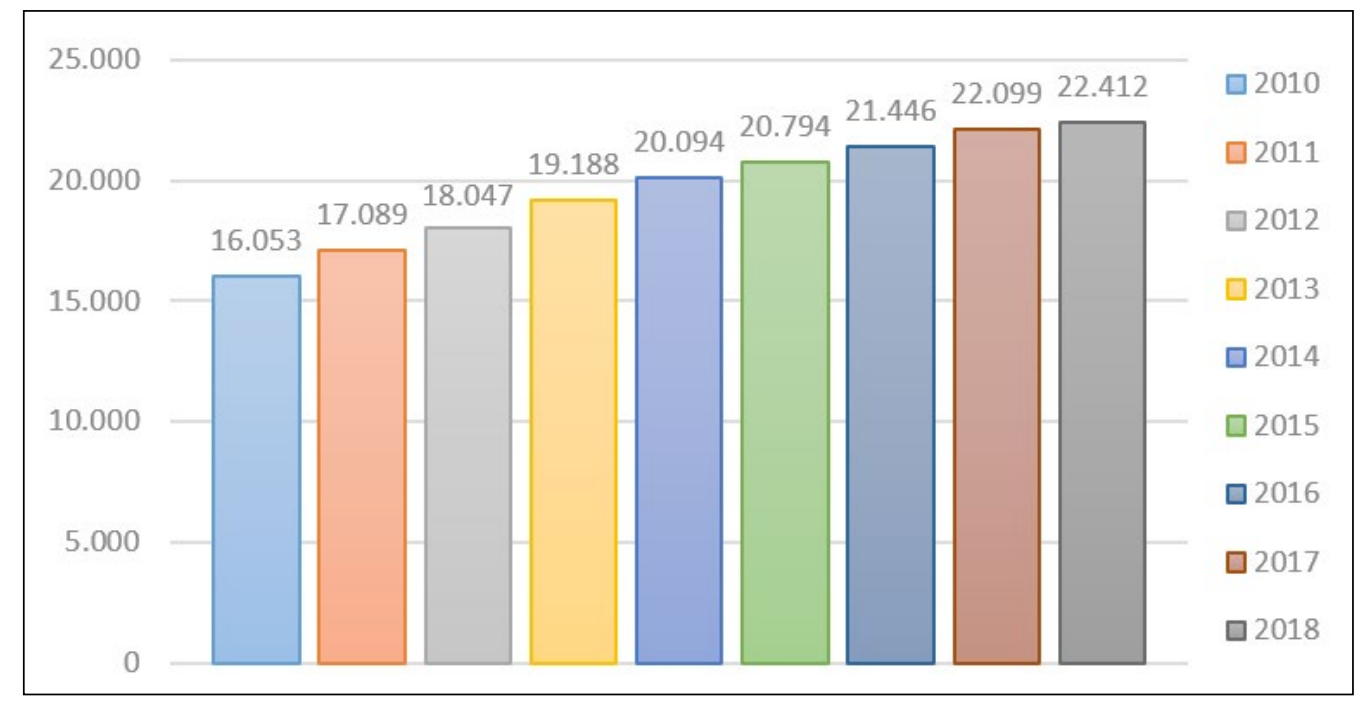

Fonte: Autora (2018) Dados: DETRAN

A frota de veículos vem aumentando a cada ano. Conforme dados do DETRAN, em 2010, a frota de veículos foi de 16.053, com uma população de 27.272 pessoas, a média foi de 0,59 veículos/habitante. Em 2018, a frota de veículos é de 22.412 , considerando que a população estimada do município é de 32.676 pessoas, chega-se a uma média de 0,69 veículos/habitante.

\subsection{Polaridades}

Quanto aos equipamentos públicos do município, percebe-se que não existe uma boa distribuição em seu território. Os principais equipamentos encontram-se concentrados nos núcleos dos bairros Teutônia, Languiru e Canabarro, sendo que neste último, já estão um pouco melhor distribuídos. As praças também se concentram nestes núcleos, porém, percebe-se a falta de um parque, que seja um espaço maior, com abrangência para todo o município. 


\subsection{Sistema Viário}

Em relação ao sistema viário, destacam-se as vias de maior porte, de acesso e transição pela cidade, a RSC-453 (Rota do Sol) e a ERS-128 (Via Láctea). Já dentro da cidade, podem ser consideradas como vias arteriais: a Estrada Velha (Ruas Daltro Filho, Três de Outubro e Carlos Arnt), que une os bairros Teutônia, Languiru, Centro Administrativo e Canabarro; a Rua Maurício Cardoso, que dá acesso à cidade de Westfália pelo lado leste e a RSC-453 (Rota do Sol) pelo lado oeste, indo em direção ao interior do município; a Rua Erno Dahmer, que interliga os bairros Languiru e Alesgut, onde localizam-se pontos de comércio importantes, indústria, além de ser uma via de tráfego intenso em certos horários do dia, gerando muitas vezes congestionamentos; a Rua 25 de Julho, que interliga os bairros Languiru, Boa Vista e segue em direção ao interior e a cidade de Poço das Antas; a Rua Major Bandeira, que interliga os bairros Alesgut, Languiru e termina na Rua 25 de Julho ao lado leste, ao oeste, segue em direção ao interior; a Avenida 1 Leste, que interliga os bairros Languiru, Centro Administrativo e Canabarro; no bairro Canabarro, as Ruas 17 de Junho e Duque de Caxias interligam a cidade com o interior e a Rua Tiradentes, interliga a ERS-453 (Via Láctea) com a Rua Carlos Arnt. Nos bairros Teutônia, Languiru e Canabarro, existem algumas ruas de sentido único, assim como, nos dois últimos bairros, nas vias com maior movimentação, existe o estacionamento rotativo. 
Figura 21 - Mapa da cidade: Hierarquia Viária

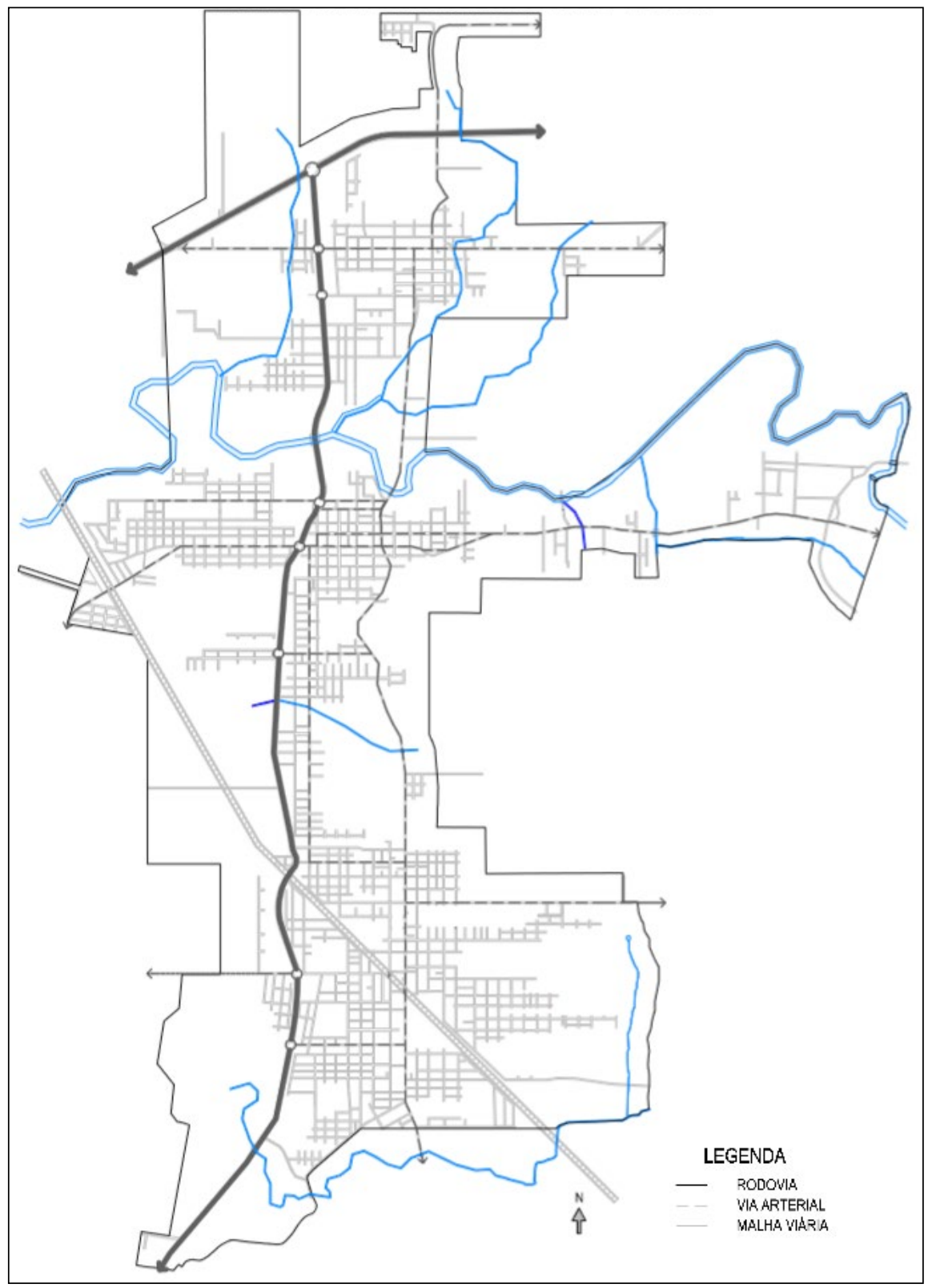

Fonte: Autora (2018).

\subsection{Morfologia Urbana / Ambiente Construído}

Os usos do solo, seguem a mesma lógica da distribuição dos equipamentos públicos. Possuem uma maior variedade de usos nas centralidades dos bairros Teutônia, Languiru e Canabarro. Destaca-se um corredor de comércio e serviços 
ao longo da RSC-453 (Rota do Sol) e da ERS-453 (Via Láctea). Nas periferias dos bairros, e nos bairros mais próximos ao interior, a área possui predominância residencial unifamiliar.

Figura 23 - Mapa da cidade: Uso do Solo

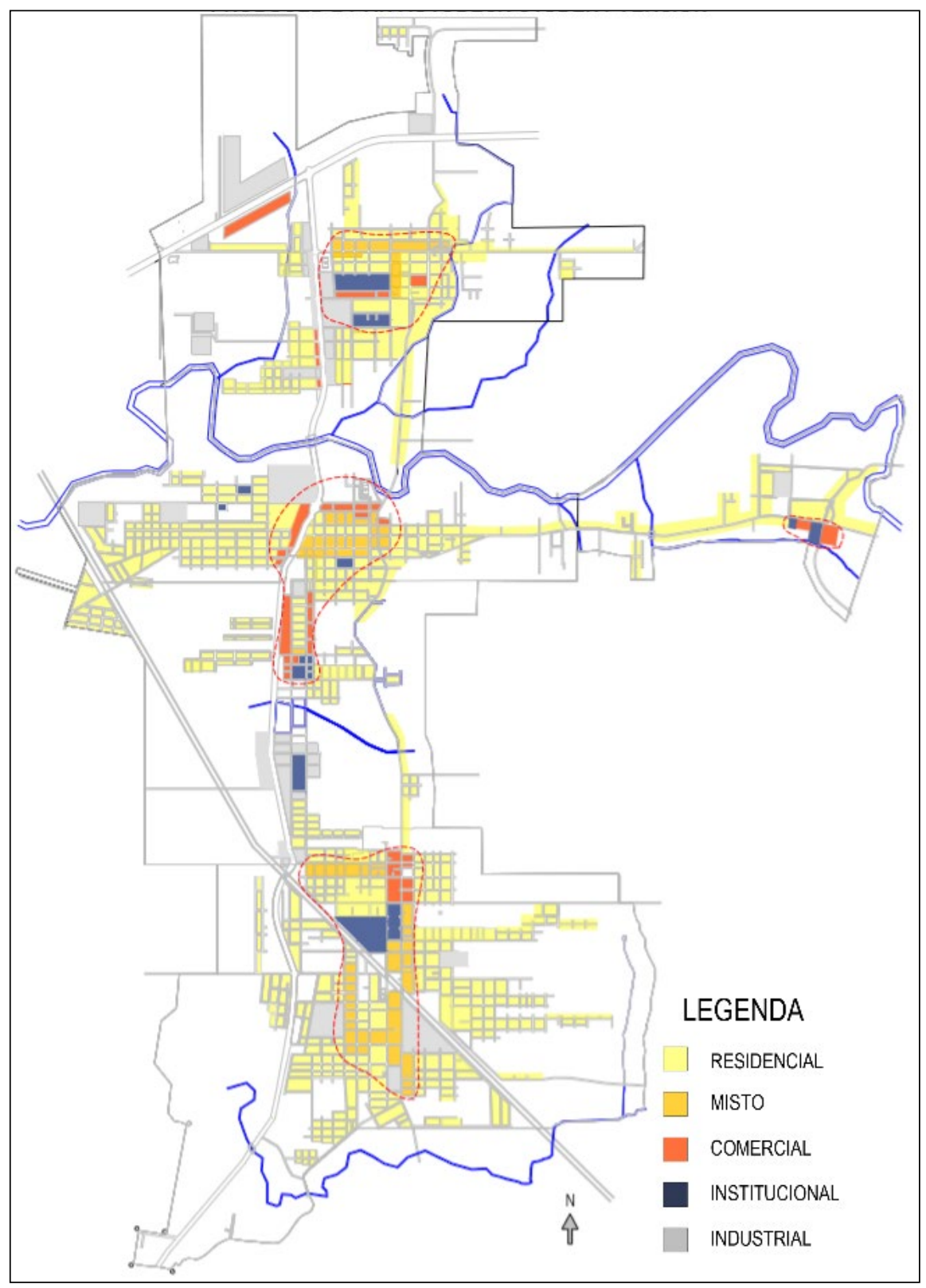

Fonte: Autora (2018). 


\subsection{Plano de Mobilidade Urbana de Teutônia}

O Plano Diretor de Mobilidade Urbana foi elaborado em 2009 pela PróCidades Consultores Associados. Nele, é previsto algumas prioridades para a integração do território municipal:

- Construção de outros pontos de passagem pela ferrovia, além dos já existentes, com a finalidade de estimular a ocupação urbana nestas áreas, que já possuem infraestrutura, mas se encontram desocupadas por falta de conexões interbairros mais próximas;

- Criação de uma via urbana paralela a ERS-128 (Via Láctea), de forma a evitar o uso de "links" (trechos) sobre a rodovia para as conexões interbairros;

- Complementações viárias, para conexões estratégicas em regiões de vazios urbanos existentes, permitindo o desenvolvimento e expansão urbana de forma mais integrada;

- Reorganização da circulação viária nos três centros de bairros, com o objetivo de melhorar a fluidez, diminuir conflitos, aumentar a segurança viária e priorizar a circulação do transporte público pela área;

- Revisão das travessias da ERS-128 (Via Láctea), com a criação de rotatórias fechadas, principalmente no cruzamento da Rua Major Bandeira, que é o principal eixo de transposição da rodovia no sentido leste/oeste;

- Criação de infraestrutura para circulação de pedestres e ciclistas, evitando a circulação de alto risco nas vias públicas e bordas da rodovia;

- Reurbanização dos espaços centrais dos núcleos de bairro com a criação de espaços de vivência e vias de tráfego amigável, com a implantação de medidas de Traffic Calming.

- Transporte público para atender bairros residenciais de maior densidade populacional com distâncias inferiores a 250 metros;

- Ligação de todos os bairros com um centro de comércio e serviços de bairro e com o Centro Administrativo.

Em relação a rede de transporte público, o Plano cria 4 linhas de transporte de caráter estrutural. Estas devem atender os principais deslocamentos pelo espaço urbano. Os principais corredores das linhas de circulação de circulação do transporte coletivo são: a Avenida 1 Oeste e a Estrada Velha - no sentido norte sul; e as Ruas Major Bandeira e 25 de Julho - no sentido leste oeste.

A cobertura da rede de transportes públicos atende boa parte da cidade, ficando de fora apenas três áreas centrais da cidade que atualmente ainda são vazios urbanos ou áreas de baixa densidade. No entanto, nas extremidades, houve crescimento tanto ao leste, no bairro Canabarro, quanto ao Oeste, nos bairros Teutônia, Alesgut e Centro Administrativo. Isso faz com que uma parcela da população tenha necessidade de caminhar distâncias maiores, até o corredor de transporte coletivo. 
O Plano de Mobilidade prevê também vias preferenciais a pedestres, formando um circuito peatonal, com extensão de $8,5 \mathrm{~km}$. Este circuito conecta os centros dos bairros Teutônia, Languiru, Centro Administrativo e Canabarro. Também faz a projeção da ciclovia que une os bairros Teutônia a Canabarro através de uma rota circular com extensão de $15,8 \mathrm{~km}$ passando por algumas das principais ruas da cidade. Além disso, projeta um eixo no sentido leste/ oeste, interligando os bairros Alesgut e Languiru com extensão de 3,9 km. Atualmente, nenhuma dessas projeções foi realizada.

\section{PROGNÓSTICO}

O capítulo apresenta conclusões realizadas a partir das referências teóricas estudadas e o diagnóstico de Teutônia. Com base nisso, serão elaboradas estratégias para as intervenções urbanísticas necessárias no município.

\subsection{Mobilidade Urbana de Teutônia}

A mobilidade urbana da cidade possui sérias deficiências. A ERS128 (Via Láctea), corta a cidade no sentido norte-sul, dificultando o acesso de pessoas de um ponto ao outro pelo grande fluxo de veículos, levando em consideração que é a principal via utilizada para acesso entre bairros. Esta rodovia não possui um espaço adequado para a circulação de pedestres e ciclistas, porém, é muito utilizada por este grupo de pessoas, visto que o outro lado, ao leste da cidade, possui ocupação predominantemente residencial e a população necessita deslocar-se aos centros urbanos.

Gehl (2013) afirma que é importante criar tipos de ruas e soluções para o tráfego a partir da escala humana, tornando o deslocamento confortável e seguro. O PlanMob também relaciona como necessidade para a cidade, $\mathrm{o}$ planejamento das ruas de forma que pedestres e ciclistas tenham condições adequadas e seguras de locomoção pela cidade. Para esta questão, poderiam ser adotadas, por exemplo, vias laterais para reorganização do fluxo intermunicipal separado do intramunicipal.

Castello (2008) diz que é importante que todo o sistema viário tenha pelo menos três tipos de vias: arteriais, coletoras e locais. Assim como, também lembra que cada rua tem características diferentes, portanto, deve ter a configuração e a dimensão de acordo com a sua função. A cidade de Teutônia não apresenta uma hierarquia viária clara em determinadas ruas, dificultando a identificação de vias coletoras e locais, o que também atrapalha o trânsito. A partir das referências estudadas, pode-se sugerir que ruas locais tenham maior espaço dedicado ao pedestre e espaços de convívio para as pessoas, diminuindo as faixas de rolamento para veículos. Isso dificultaria a utilização de vias locais como acesso entre as vias arteriais.

A cidade não possui ciclovia. Existe uma ciclofaixa, separada por tachões da faixa de veículos de fluxo rápido, na Estrada Velha (Ruas Carlos 
Arnt e Três de Outubro) que conecta o bairro Canabarro e Languiru. O espaço não é convidativo para ser utilizado, pois não gera segurança e em certos pontos possui altas declividades, tornando o caminho desconfortável. Esta ciclofaixa possui uma interrupção no centro do bairro Languiru, aonde existe um grande fluxo de veículos, sendo que este trecho ainda possui ocupação de estacionamento, nos dois lados da via. Após o centro do bairro, a ciclofaixa continua na conexão entre o bairro Languiru e o bairro Teutônia, porém, em formato de calçada.

Para atender a todos os tipos de deslocamentos, Farr (2013) sugere as ruas completas, podendo ser utilizados diferentes tipos de transporte, como ônibus, automóveis, bicicletas e o passeio, para os pedestres. Isso gera a conexão entre a ciclofaixa, assim como também, transforma o espaço urbano, trazendo uma maior valorização aos pedestres e ciclistas. Para a viabilidade da proposta, é importante tirar o estacionamento desta via.

As calçadas da cidade, em geral, possuem uma largura pequena, não estão em bom estado de conservação e não possuem os requisitos de acessibilidade. São pouco utilizadas, sendo que a maior parte das pessoas utiliza carro, gerando grandes fluxos e congestionamentos, enquanto as calçadas permanecem praticamente vazias. Em alguns locais, como no bairro Teutônia, aonde a população da parte do centro do bairro caminha com uma frequência um pouco maior, principalmente na entrada e saída das indústrias, parte das pessoas utiliza a faixa de veículos, devido ao tamanho pequeno do passeio. Tem-se como exceção, o bairro Languiru, aonde já existem algumas calçadas de acordo com as normas de acessibilidade, mas também de tamanho inferior à sua demanda.

Castello (2008) explica que algumas ações projetuais podem transformar as ruas e trazer mudanças significativas na interação social da comunidade. Farr (2013) também contribui, afirmando que o tratamento da rua, quando possui um ambiente amigável, funcional e com uma infraestrutura adequada, influencia diretamente no estilo de vida, como também no comportamento das pessoas. Projetos permeáveis ao pedestre trazem maior disposição para as pessoas caminharem, até mesmo, quando forem distâncias maiores até o local de destino. Por isso, é importante tirar o estacionamento de vias arteriais e aumentar o passeio, para melhorar o espaço de pedestres, como também implantar ciclofaixas, aonde houver a necessidade. Isso gera mais conforto e melhora a segurança do pedestre, assim como também traz mais vida ao local.

\subsection{Uso do solo}

$\mathrm{Na}$ análise de distribuição de usos da cidade, percebe-se a presença de três centros urbanos bem definidos, localizados nos bairros Teutônia, Languiru e Canabarro. Estes locais possuem uma boa distribuição de usos, o que é um fator positivo para a cidade, pois todos os autores estudados asseguram que o 
uso misto contribui para melhorar a mobilidade urbana e a qualidade de vida das pessoas.

Destaca-se na ocupação do solo também, um corredor de comércio e serviços ao longo da ERS-128 (Via Láctea). Gehl (2013) explica a importância da transição entre o tráfego rápido e lento, que não deve acontecer próximo as residências. Então, percebe-se que a utilização do solo foi realizada de forma adequada, contribuindo para uma melhor qualidade do espaço, pois a transformação da paisagem foi realizada de forma gradual, até chegar na ocupação residencial.

\subsection{Equipamentos Urbanos}

A distribuição dos equipamentos urbanos pela cidade também é deficitária, tendo uma maior predominância nos centros dos bairros Teutônia, Languiru e Canabarro. A baixa densidade populacional dificulta a distribuição dos equipamentos, sendo que as grandes distâncias a serem percorridas entre a moradia e os equipamentos tornam-se um problema. Tanto Castello (2008) quanto Farr (2013) ressaltam a importância da proximidade entre moradia, serviços e equipamentos urbanos, para trazer vida a cidade.

As indústrias possuem boas localizações e estão bem distribuídas pela cidade. Geralmente situam-se próximo as vias arteriais, possibilitando fácil acesso e com uma certa distância das residências.

Já em relação aos espaços abertos, como parques e praças, percebe-se que são pouco valorizados, por todo o perímetro urbano. Existe apenas um parque localizado na parte sul, no bairro Canabarro, sendo muito distante para a maioria da população que não mora naquele local. Farr (2013) ressalta a importância destes locais por se tornarem "terceiros lugares", propiciando espaços de encontros sociais e possibilitando a convivência entre gerações. De acordo com Castello (2008), para obter sucesso na implantação destes equipamentos, devem ser considerados o tipo de equipamento adequado em cada área, a sua localização e tamanho adequado. A autora também lembra da importância dos corredores de sustentabilidade e afirma que a organização sistêmica dos espaços abertos pode facilitar a movimentação das pessoas na cidade, sugerindo uma distância de 10 minutos entre estes espaços. Gehl (2013) também contribui, afirmando que as pessoas permanecem em locais onde a qualidade do espaço urbano seja convidativa.

\subsection{Densidade}

Tanto os autores Leite (2012), como Farr (2013) destacam a importância da densidade para um urbanismo sustentável. Percebe-se isso como um ponto negativo em Teutônia, pois a maior parte da cidade possui pouca densidade e através dos estudos realizados, percebeu-se que a tendência de crescimento da cidade é voltada na dispersão, ao invés de aumentar a densidade do espaço 
urbano existente. Essa dispersão da cidade também é facilitada pelo tamanho do perímetro urbano, que é grande, em relação ao número de habitantes. Com isso, o transporte público acaba tornando-se caro, além de aumentar as distâncias entre moradia e outros equipamentos urbanos, o que estimula ainda mais o uso do automóvel particular.

Uma das formas de resolver este problema é diminuindo o perímetro urbano e estimulando a ocupação nas áreas centrais da cidade. Para isso, também é de grande importância a utilização dos instrumentos urbanísticos estudados no Estatuto da Cidade, exigindo que os terrenos cumpram a sua função social. Outra estratégia interessante é a densificação das áreas próximas aos eixos de transporte coletivo. Através do incentivo nos usos mistos deste espaço também, como térreo comercial e de serviços, cria-se um espaço melhor ocupado e com necessidade de percorrer distâncias menores, além do estímulo na utilização do transporte público. Quanto mais pessoas utilizarem este meio de transporte, mais acessível ele se torna a população.

De acordo com Leite (2013), a maior densidade otimiza a infraestrutura urbana e propicia uma melhor qualidade de vida através da sobreposição de usos (habitacional, comercial e de serviços). Para tanto, nota-se que o problema de baixa densidade na cidade está relacionado com todo o planejamento urbano realizado. As deficiências dos outros itens citados anteriormente, como a hierarquização das vias e a distribuição dos usos do solo interligam-se diretamente com a densidade urbana. Para obter melhores resultado, a cidade deve ser compacta.

\section{CONCLUSÃO}

As cidades atuais precisam buscar novos modelos de funcionamento, a fim de garantir um crescimento urbano organizado e mais sustentável, diferente de como acontecia no século XX. Para isto, é fundamental levar em consideração o aprimoramento da mobilidade urbana, trazendo um maior espaço voltado ao pedestre e incentivando os usos mistos e a compacidade das cidades, tornandose possível o deslocamento a pé para a realização das atividades do dia a dia.

Após estudar os três autores: Leite (2012), Gehl (2013) e Farr (2013), percebe-se que todos concordam que o modelo de cidade compacta com densidades qualificadas são fatores positivos e necessários para uma cidade sustentável. A densidade influencia no bom funcionamento da cidade, em relação a utilização do comércio e equipamentos urbanos, facilita a maior variedade e melhorias na mobilidade urbana, pois sustenta os custos que são rateados por mais pessoas, melhora a qualidade de vida das pessoas e desenvolve a economia local. Incluindo-se ainda, o uso misto do solo, multicentralidades ligadas por uma rede de mobilidade de transporte público eficientes, ciclovias, áreas adequadas ao pedestre e desenvolvimento econômico local rico, têm-se boas oportunidades atrativas para a cidade. 
Para uma boa permeabilidade nas ruas, são necessários a diversidade de usos do solo, bons equipamentos urbanos, assim como a presença de mais pessoas transitando pelos locais. Esse conjunto de fatores torna a rua mais segura e agradável para a utilização de pedestres.

Conclui-se que a sustentabilidade nas cidades é voltada principalmente para uma melhor qualidade de vida das pessoas: facilita os acessos, cria espaços de convivência atrativos, aproxima a moradia do trabalho e do lazer e valoriza as questões de preservação ambiental e saúde da população. A mobilidade urbana sustentável maximiza as possibilidades de escolha modal, valorizando os transportes não motorizados, assim como também incentiva a vida em comunidade. Em suma, para se obter bons resultados, é importante integrar a mobilidade com o planejamento urbano das cidades.

\section{REFERÊNCIAS}

BRASIL. MINISTÉRIO DAS CIDADES. PlanMob: Caderno de Referência para elaboração de Plano de Mobilidade Urbana. Brasília: Ministério das Cidades, 2015.

CASTELLO, Iára Regina. Bairros, loteamentos e condomínios: Elementos para o projeto de Novos Territórios Habitacionais. Porto Alegre: UFRGS, 2008.

CENSO, I.B.G.E. Instituto Brasileiro de Geografia e Estatística. 2010.

Sinopse por Setores. Disponível em: <https://censo2010.ibge.gov.br/ sinopseporsetores/?nivel=st> Acesso em 31. ago. 2018.

CIDADES, I.B.G.E. Instituto Brasileiro de Geografia e Estatística. 2014. Teutônia. Disponível em: <https://cidades.ibge.gov.br/brasil/rs/teutonia/panorama > Acesso em 31 ago. 2018.

DETRAN. Secretaria da modernização administrativa e dos recursos humanos. Departamento estadual de trânsito. Frota em circulação no RS. Disponível em <http://www.detran.rs.gov.br/conteudo/27453/frota-do-rs. Acesso em 15 set. 2018.

FARR, Douglas. Urbanismo sustentável: desenho urbano com a natureza. Porto Alegre: Bookman, 2013.

GEHL, Jan; tradução DI MARCO, Anita. Cidades para pessoas. São Paulo: Perspectiva, 2013.

LEITE, Carlos; AWAD, Juliana di Cesare Marques. Cidades sustentáveis cidades inteligentes: desenvolvimento sustentável num planeta urbano. Porto Alegre: Bookman, 2012.

POPULAÇÃO.NET.BR. População Teutônia - RS. Disponível em: <http:/ /www. populacao.net.br/populacao-teutonia_rs.html>. Acesso em 01 nov. 2018. 
PREFEITURA MUNICIPAL DE TEUTÔNIA. O Município. Disponível em: <http:/ / www.teutonia.rs.gov.br/>. Acesso em 06 nov. 2018

Plano Diretor de Mobilidade Urbana do Município de Teutônia. Relatório Técnico. Teutônia, 2009.

SEBRAE. Perfil das Cidades Gaúchas Teutônia. Porto Alegre, 2017. 